\title{
Negatively Charged Red-Emitting Acridine Dyes for Facile Reductive Amination, Separation, and Fluorescent Detection of Glycans
}

\author{
Maksim A. Fomin, Jan Seikowski, Vladimir N. Belov,* and Stefan W. Hell
}

Cite This: Anal. Chem. 2020, 92, 5329-5336

Read Online

ABSTRACT: Capillary gel electrophoresis with laser-induced fluorescence detection (CGE-LIF) has become a key method in high-throughput glycan analysis. At present, CGE-LIF relies on the green fluorophore 8-aminopyrene-1,3,6-trisulfonic acid (APTS). However, APTS has moderate reactivity in labeling of glycans and a fixed selectivity profile. Here, we report synthesis of red-emitting and highly reactive fluorescent tags for glycan derivatization. The design is based on a 9-aminoacridine scaffold with various acceptor groups at $\mathrm{C}-2\left(\mathrm{CN}, \mathrm{SO}_{2} \mathrm{R}\right)$ and a primary amino group at C-7 for conjugation via reductive amination. These reactive dyes exhibit absorption maxima close to $450 \mathrm{~nm}$ and emission above $600 \mathrm{~nm}$. They readily undergo conjugation with reducing sugars at the desired

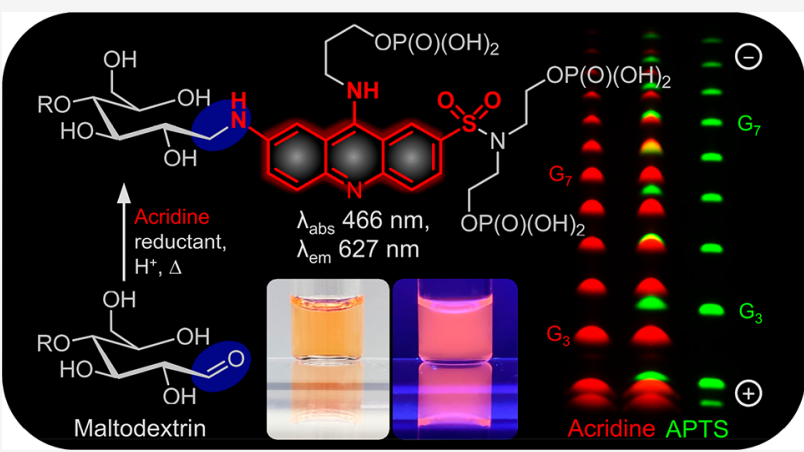
1:1 stoichiometry. The red emission of conjugates with a maximum at $610-630 \mathrm{~nm}$ can be observed under excitation with $488 \mathrm{~nm}$ light and detected separately from the APTS-labeled oligosaccharides. Phosphorylated 7,9-diaminoacridine-2- $\mathrm{SO}_{2} \mathrm{R}$ derivatives with variable amounts of negative charges provide high mobilities of glycoconjugates on polyacrylamide gel electrophoresis (PAGE), as compared with those of APTS. We further demonstrate their utility by labeling and separating a maltodextrin ladder and sialyllactose isomers. The new dyes are expected to cross-validate and increase the glycan identification precision in CGE-LIF and help to reveal "heavy" glycans, yet undetectable with the APTS label.

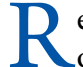
ecognition, profiling, and monitoring the concentrations of oligosaccharides (glycans) supports the discovery of disease biomarkers, ${ }^{1,2}$ therapeutic antibody development, ${ }^{3-5}$ immunology, ${ }^{6}$ and glycan engineering. ${ }^{7}$ Analysis of glycans is challenging because of their vast structural diversity and hydrophilicity. ${ }^{8,9}$ Importantly, oligosaccharide molecules lack a chromophore and, in most instances, ionizable groups. Nonetheless, great progress has been made in the analysis of glycans conjugated to asparagine or serine side chains of proteins $\left(N\right.$ - and $O$-glycans). ${ }^{8-16}$ These structures are in the focus of "glycomics", as they relate to post-translational modifications that underlie protein functions. A robust method for the high-throughput glycosylation analysis is based on the use of capillary gel electrophoresis with laser-induced fluorescence detection (CGE-LIF). ${ }^{12}$ In this approach, the enzymatically or chemically released glycans are labeled at the reducing end with fluorescent tags. ${ }^{17}$ Additionally, a net electrical charge is required for the separation of conjugates by CGE. ${ }^{9}$ Because of the gels' sieving effect, the electrophoretic mobility of a labeled glycan depends on the size (shape) of the molecule. Since these parameters are difficult to evaluate, the mass-to-charge ratio $(\mathrm{m} / z)$ is used as an estimate of the electrophoretic mobility.

Reductive amination allows to attach a fluorescent dye to a carbohydrate (Scheme S1). ${ }^{18}$ This is a stepwise procedure, which forms a covalent $\mathrm{N}-\mathrm{C}$ bond between a primary amine of the dye and an aldehyde group at the reducing end of the carbohydrate. ${ }^{16}$ To date, only few fluorescent dyes derived from benzene, naphthalene, and pyrene have been applied for reductive amination, analysis, and fluorescent detection of glycans (Figure 1). ${ }^{19}$ The design of these fluorescent tags is challenging. They must have an amino group with relatively low basicity for efficient reductive amination at $\mathrm{pH} \sim 3$, negative net charge ( -3 to -6 at $\mathrm{pH}=8$ of the CGE buffer) to provide high electrophoretic mobility, be stable against reduction with boranes or borohydrides and resistant against hydrolysis in a wide $\mathrm{pH}$ range (3-8), undergo efficient excitation with an argon ion laser $(488 \mathrm{~nm})$ or solid-state laser (505 nm), and finally, have strong green to red emission in aqueous solutions.

Conjugates of anthranilic acid (2-AA) and 8-aminonaphthalene-1,3,6-trisulfonic acid (ANTS) emit violet and

Received: December 30, 2019

Accepted: March 10, 2020

Published: March 10, 2020 


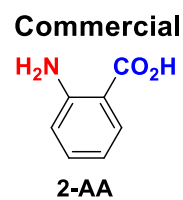

$\left(\lambda_{\text {exc }} 360 \mathrm{~nm}\right.$,

$\lambda_{\text {em }} 420 \mathrm{~nm}$ )

\section{Previous works} (HO) ${ }_{2} \mathrm{OPO}$

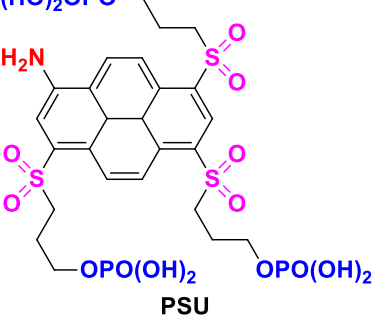

$\left(\lambda_{\text {abs }} 506 \mathrm{~nm}, \lambda_{\mathrm{em}} 558 \mathrm{~nm}\right)$<smiles>Cn1c2ccc(N)cc2c(=O)c2cc(S(=O)(=O)N(CCOP(=O)(O)O)CCOP(=O)(O)OCCOP(=O)(O)O)ccc21</smiles>

$\left(\lambda_{\text {abs }} 439 \mathrm{~nm}, \lambda_{\mathrm{em}} 597 \mathrm{~nm}\right)$

Present study

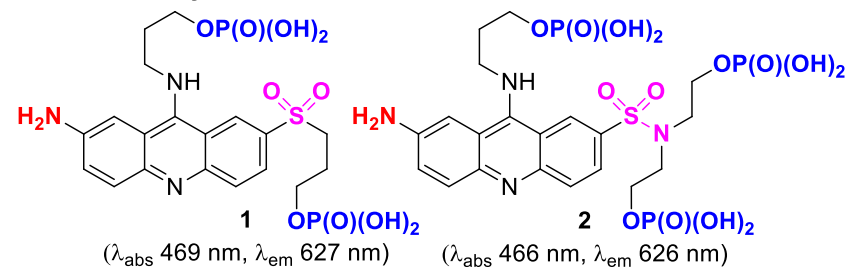

Figure 1. Commercial (2-AA, ANTS, APTS) and reported (PSU, PSN) glycan labels, as well as 7 -aminoacridone dye ASA, and new negatively charged 7,9 -diaminoacridines $(1,2)$ of the present study (with absorption and emission maxima of glycan-dye conjugates or their excitation wavelengths).

green light, respectively, and cannot be excited with an argon laser. On the contrary, conjugates of 8-aminopyrene-1,3,6trisulfonic acid (APTS) can be excited with an argon laser, and their emission is captured in the "green" color channel of LIF detectors. Therefore, due to the presence of three negatively charged sulfonic acid residues, relatively high brightness and large sensitivity of detection, APTS emerged as a benchmark dye for glycan analysis. ${ }^{20-24}$ However, the performance of APTS as a single fluorescent tag, with only one emission color, improvable brightness, and three negative charges, is limited. We have recently developed phosphorylated aminopyrenesulfone (PSU) and -sulfonamide (PSN) dyes for reductive amination of glycans. ${ }^{25}$ The conjugates of these dyes have absorption and emission maxima at ca. 500 and $560 \mathrm{~nm}$, respectively, six negative charges $(\mathrm{pH} \geq 8)$, low $m / z$ ratios, and they are ca. 3 times brighter than APTS derivatives (under excitation with the $488 \mathrm{~nm}$ light). We also disclosed 7aminoacridone-2-sulfonamide (ASA) with two phosphate groups, which emits orange light. ${ }^{26}$ However, fluorescent tags with red emission were missing, though they are highly desired for glycan sensing in the "red" channel of a LIF detector. In particular, glycans labeled with such dyes can be used as reference compounds and standards for calibration of retention times in CGE-LIF. ${ }^{27}$
Currently, labeled glycans are identified by comparison of their migration times with the so-called "LIZ DNA Ladder", which is added to the sample and injected together with labeled analytes in each run. ${ }^{13}$ However, the DNA-based standard is not an ideal marker. ${ }^{9,28,29}$ The structures and shapes of DNA molecules are very different from those of natural glycans. Therefore, the migration parameters of the DNA-based standards drift (change in time) differently than those of dye-labeled glycans. Therefore, up to now, the usability and reproducibility of CGE-LIF for glycan analysis is compromised by improper and imprecise alignment of migration times of the analytes. The new fluorescent dyes capable of reductive amination are highly needed to create better internal standards based on glycan oligomers of various lengths. ${ }^{13}$ The "second dye" complementary to APTS (not only in respect of emission) could also provide a different selectivity profile for complex mixtures of carbohydrates. Thus, the new set of migration times based on a new fluorescent tag would enable us to create new databases for glycan identification.

Herein, we report the negatively charged red-emitting acridine dyes $(\mathbf{1}, \mathbf{2})$ that allow facile labeling of carbohydrates. These compounds are based on the 9-aminoacridine scaffold, modified with an acceptor group in position 2 and a primary amino group at C-7. The dyes were decorated with primary phosphate residues enabling applications in gel electrophoresis. The conjugates with glucose and maltose oligomers were readily prepared via reductive amination. The excitation with $488 \mathrm{~nm}$ light (and even $505 \mathrm{~nm}$ light) is possible. The Stokes shifts turned out to be large (ca. $160 \mathrm{~nm}$ ) enabling the detection in a spectral window fully separated from the fluorescence of APTS conjugates. Because of the presence of multiple negative charges, the obtained glycoconjugates showed high electrophoretic mobilities. In particular, conjugates of compound $\mathbf{2}$ move faster than the corresponding APTS derivatives.

\section{EXPERIMENTAL SECTION}

Synthesis of acridines 2-7, acridone 29, intermediates 17, 20 and glycoconjugates, and more detailed experimental procedures and HPLC conditions are described in the Supporting Information.

General Procedure 1 (GP1) for Phosphorylation of Alcohols (Compound 23). Diol 17 (330 mg, $0.79 \mathrm{mmol}$ ) and $1 \mathrm{H}$-tetrazole $(330 \mathrm{mg}, 4.72 \mathrm{mmol}$ ) were placed into an Arfilled flask, which was evacuated and backfilled with $\operatorname{Ar}(3 \times)$.

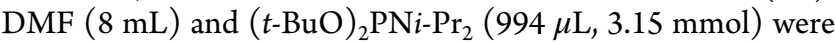
added, and the reaction mixture was stirred for $1 \mathrm{~h}$ at $\mathrm{rt}$. Formation of the phosphite intermediate was monitored by $\operatorname{HPLC}\left(t_{\mathrm{R}}=14.3 \mathrm{~min}\right.$, gradient $\left.5-50\right)$. Then $50 \%$ aq. $\mathrm{H}_{2} \mathrm{O}_{2}$ $(358 \mu \mathrm{L}, 7.3 \mathrm{mmol})$ was added in one portion. After it was stirred at rt for $30 \mathrm{~min}$, the mixture was diluted with DCM $(200 \mathrm{~mL})$, washed with $10 \%$ aq. $\mathrm{Na}_{2} \mathrm{SO}_{3}$ - sat. aq. $\mathrm{NaHCO}_{3}$ $(100 \mathrm{~mL}, 1: 1)$ and brine, dried $\left(\mathrm{Na}_{2} \mathrm{SO}_{4}\right)$, and concentrated in vacuo. The residue was purified by flash chromatography $\left(\mathrm{SiO}_{2}, 15 \mathrm{SIHP}-\mathrm{F} 0040\right.$ cartridge, DCM/MeOH with $2-5 \%$ $\mathrm{MeOH}$ gradient) to give a light orange solid (260 mg, 41\%). TLC $\left(\mathrm{SiO}_{2}\right): R_{\mathrm{f}}=0.3(\mathrm{DCM} / \mathrm{MeOH} 20: 1)$. HPLC: $t_{\mathrm{R}}=10.9$ $\min$ (gradient 20-100); $t_{\mathrm{R}}=17.6 \mathrm{~min}$ (gradient 5-50); $\lambda_{\max }=$ 427, 410, 357, 303, 267 nm. HRMS: $m / z 804.3056$ ([M + $\mathrm{H}]^{+}$) calculated for $\mathrm{C}_{35} \mathrm{H}_{56} \mathrm{~N}_{3} \mathrm{O}_{12} \mathrm{P}_{2} \mathrm{~S}^{+}: 804.3054(\Delta 0.2 \mathrm{ppm})$. ${ }^{1} \mathrm{H}$ NMR (400 MHz, MeOD- $d_{3}$ with TFA- $d$ ): $\delta=9.29-9.75$ (m, 1H), 8.89-9.28 (m, 1H), $8.75(\mathrm{dd}, J=9.4,2.3 \mathrm{~Hz}, 1 \mathrm{H})$, $8.42(\mathrm{dd}, J=9.0,1.6 \mathrm{~Hz}, 1 \mathrm{H}), 8.00(\mathrm{~d}, J=9.0 \mathrm{~Hz}, 1 \mathrm{H}), 7.95$ 
$(\mathrm{d}, J=9.4 \mathrm{~Hz}, 1 \mathrm{H}), 4.36(\mathrm{t}, J=6.7 \mathrm{~Hz}, 2 \mathrm{H}), 4.19(\mathrm{q}, J=6.7$, 6.3, $5.9 \mathrm{~Hz}, 2 \mathrm{H}), 4.06(\mathrm{q}, J=7.4,6.3 \mathrm{~Hz}, 2 \mathrm{H}), 3.42-3.52(\mathrm{~m}$, $2 \mathrm{H}), 2.44$ (quin, $J=6.3 \mathrm{~Hz}, 2 \mathrm{H}), 2.04-2.17(\mathrm{~m}, 2 \mathrm{H}), 1.44(\mathrm{~s}$, 9H), 1.44 (s, 9H), 1.42 (s, 18H) ppm. ${ }^{31} \mathrm{P}$ NMR (162 MHz, $\left.\mathrm{CDCl}_{3}\right): \delta=-8.0$ (br s, 1P), -10.1 (s, 1P) ppm. Note: compound 23 is slowly hydrolyzed into the corresponding acridone (within hours) in MeOD- $d_{3} /$ TFA- $d$.

GP2 for Reduction of Nitro Compounds (Compound 24). Nitroacridine 23 (50 mg, $62 \mu \mathrm{mol}$ ) was dissolved in $\mathrm{MeOH}(4 \mathrm{~mL})$ and $\mathrm{AcOH}(20 \mu \mathrm{L})$ under Ar. The catalyst $(10 \% \mathrm{Pd} / \mathrm{C}, 5 \mathrm{mg})$ was added, the mixture was flushed with $\mathrm{Ar}$, and hydrogen atmosphere was applied. After stirring for $1 \mathrm{~h}$ at $\mathrm{rt}$, orange fluorescent solution was filtered through a pad of Celite and concentrated in vacuo. The residue was dissolved in $10 \mathrm{~mL}$ of ACN/0.1\% aq. TFA (1:5) and purified by flash chromatography (C18 silica gel, 15C18AQ-F0025 cartridge, ACN $-0.1 \%$ aq. TFA, $0-100 \%$ ACN, 20 column volumes). The appropriate fractions were pooled and lyophilized to give a red powder (42 mg, 76\%, TFA salt). HPLC: $t_{\mathrm{R}}=10.3 \mathrm{~min}$ (gradient 20-100). HRMS: $m / z 774.3315\left([\mathrm{M}+\mathrm{H}]^{+}\right)$ calculated for $\mathrm{C}_{35} \mathrm{H}_{58} \mathrm{~N}_{3} \mathrm{O}_{10} \mathrm{P}_{2} \mathrm{~S}^{+}: 774.3313(\Delta 0.3 \mathrm{ppm}) .{ }^{1} \mathrm{H}$ NMR (400 MHz, MeOD- $\left.d_{3}\right): \delta=9.02(\mathrm{~d}, J=1.6 \mathrm{~Hz}, 1 \mathrm{H})$, $8.21(\mathrm{dd}, J=9.0,1.6 \mathrm{~Hz}, 1 \mathrm{H}), 7.91(\mathrm{~d}, J=9.0 \mathrm{~Hz}, 1 \mathrm{H}), 7.69$ (dd, $J=7.4,2.3 \mathrm{~Hz}, 1 \mathrm{H}), 7.53(\mathrm{~s}, 1 \mathrm{H}), 7.54(\mathrm{dd}, J=7.4,2.3$ $\mathrm{Hz}, 1 \mathrm{H}), 4.32(\mathrm{t}, J=7.0,6.7 \mathrm{~Hz}, 2 \mathrm{H}), 4.20(\mathrm{q}, J=6.3,5.9 \mathrm{~Hz}$, $2 \mathrm{H}), 4.06(\mathrm{q}, J=7.8,6.3,5.9 \mathrm{~Hz}, 2 \mathrm{H}), 3.45(\mathrm{~m}, J=7.8,7.4$, 2.3, $2.0 \mathrm{~Hz}, 2 \mathrm{H}$ ), 2.38 (quin, $J=6.3,5.9 \mathrm{~Hz}, 2 \mathrm{H}$ ), 2.05-2.16 $(\mathrm{m}, 2 \mathrm{H}), 1.45(\mathrm{~s}, 18 \mathrm{H}), 1.44(\mathrm{~s}, 18 \mathrm{H}) \mathrm{ppm}$. The following signals were visible in ${ }^{13} \mathrm{C} \mathrm{NMR}\left(100 \mathrm{MHz}, \mathrm{MeOD}-d_{3}\right): \delta=$ $156.5,146.7,140.6,132.7,130.3,128.2,127.4,120.0,119.8$, $115.4,110.5,102.4,83.3\left(\mathrm{~d}, J_{\mathrm{CP}}=7.6 \mathrm{~Hz}\right), 83.2\left(\mathrm{~d}, J_{\mathrm{CP}}=7.6\right.$ $\mathrm{Hz}), 64.7\left(\mathrm{~d}, J_{\mathrm{CP}}=6.9 \mathrm{~Hz}\right), 64.5\left(\mathrm{~d}, J_{\mathrm{CP}}=6.9 \mathrm{~Hz}\right), 51.9,46.0$, $29.7\left(\mathrm{~d}, J_{\mathrm{CP}}=7.6 \mathrm{~Hz}\right), 28.7,28.66,23.7\left(\mathrm{~d}, J_{\mathrm{CP}}=6.9 \mathrm{~Hz}\right) \mathrm{ppm}$. ${ }^{31} \mathrm{P}$ NMR $\left(162 \mathrm{MHz}, \mathrm{MeOD}-d_{3}\right): \delta=-10.61$ (s, 1P), -10.62 (s, 1P) ppm.

GP3 for Cleavage of tert-Butyl Groups (Compound 1). Aminoacridine 24 (43 mg, $48 \mu \mathrm{mol}$ ) was stirred in 5\% TFA in $\mathrm{DCM}(\mathrm{v} / \mathrm{v}, 4 \mathrm{~mL})$ for $4 \mathrm{~h}$ at $\mathrm{rt}$ under Ar. The reaction mixture was concentrated in vacuo (without heating), the residue dissolved in $10 \mathrm{~mL}$ of cold triethylammonium bicarbonate (TEAB, $1.0 \mathrm{M}, \mathrm{pH} 8$ ) and purified by flash chromatography (C18 silica gel, 15C18AQ-F0025, ACN - 20 mM TEAB pH 8, $0-5 \%$ ACN, 15 column volumes). The appropriate fractions were pooled and lyophilized to give a red powder $(20 \mathrm{mg}, 65 \%$, TEA salt). HPLC (Knauer Eurospher II 100-5 C18A): $t_{\mathrm{R}}=$ 9.3 min (gradient TEAB-0-25); $\lambda_{\max }=455,303,273 \mathrm{~nm}$. HRMS: $m / z$ 550.0805 $\left([\mathrm{M}+\mathrm{H}]^{+}\right)$calculated for $\mathrm{C}_{19} \mathrm{H}_{26} \mathrm{~N}_{3} \mathrm{O}_{10} \mathrm{P}_{2} \mathrm{~S}^{+}: 550.0809$ ( $\left.\Delta 0.7 \mathrm{ppm}\right) .{ }^{1} \mathrm{H}$ NMR $(400$ $\left.\mathrm{MHz}, \mathrm{D}_{2} \mathrm{O}\right): \delta=8.35(\mathrm{~s}, 1 \mathrm{H}), 7.94(\mathrm{dd}, J=9.0,1.6 \mathrm{~Hz}, 1 \mathrm{H})$, $7.49(\mathrm{~d}, J=9.0 \mathrm{~Hz}, 1 \mathrm{H}), 6.94-7.13(\mathrm{~m}, 2 \mathrm{H}), 6.83(\mathrm{~s}, 1 \mathrm{H})$, 4.06-4.22 (m, 2H), 3.85-3.98 (m, $4 \mathrm{H}), 3.46-3.59(\mathrm{~m}, 2 \mathrm{H})$, $3.18(\mathrm{q}, J=7.2 \mathrm{~Hz}, 6 \mathrm{H}, \mathrm{TEA}), 2.09-2.20(\mathrm{~m}, 2 \mathrm{H}), 1.98-2.08$ $(\mathrm{m}, 2 \mathrm{H}), 1.26(\mathrm{t}, J=7.2 \mathrm{~Hz}, 9 \mathrm{H}$, TEA) ppm. The following signals were visible in ${ }^{13} \mathrm{C}$ NMR $\left(100 \mathrm{MHz}, \mathrm{D}_{2} \mathrm{O}, \mathrm{HSQC}\right): \delta=$ 154.1, 145.3, 139.9, 130.7, $130.1(\mathrm{CH}), 128.1(\mathrm{CH}), 127.2$ $(\mathrm{CH}), 120.3(\mathrm{CH}), 119.6(\mathrm{CH}), 114.0,63.9\left(\mathrm{CH}_{2}\right), 63.1(\mathrm{~d}$, $\left.\mathrm{CH}_{2}, J_{\mathrm{CP}}=5.3 \mathrm{~Hz}\right), 52.3\left(\mathrm{CH}_{2}\right), 46.9\left(\mathrm{CH}_{2}\right), 46.7\left(3 \times \mathrm{CH}_{2}\right.$, TEA), $29.7\left(\mathrm{CH}_{2}\right), 23.7\left(\mathrm{~d}, \mathrm{CH}_{2}, J_{\mathrm{CP}}=6.9 \mathrm{~Hz}\right), 8.3\left(3 \times \mathrm{CH}_{3}\right.$, TEA) ppm. ${ }^{31} \mathrm{P}$ NMR $\left(162 \mathrm{MHz}, \mathrm{D}_{2} \mathrm{O}\right): \delta=0.35$ (s, 1P), 0.25 (s, 1P) ppm.

Note. ${ }^{13} \mathrm{C}$ NMR spectra of (phosphorylated) 9-hydroxyalkylaminoacridines recorded in various deuterated solvents
(MeOD- $d_{3}$ and $\mathrm{D}_{2} \mathrm{O}$ with or without TFA- $d ; \mathrm{CDCl}_{3}, \mathrm{DMF}-d_{7}$ or DMSO- $d_{6}$ ) appear partially unresolved.

GP4 for Labeling of Mono- and Oligosaccharides with Negatively Charged Amino-Dyes. A $1.5 \mathrm{~mL}$ micro tube with a screw cap was charged with dye (1 equiv, $0.1 \mathrm{M}$ solution in water), carbohydrate (0.5-5 equiv, $0.05-0.5 \mathrm{M}$ solution in water), malonic acid (10 equiv, $1 \mathrm{M}$ solution in DMSO), and 2-picoline-borane complex (10 equiv, $1 \mathrm{M}$ solution in DMSO). After vortexing for $10 \mathrm{~s}$, the reaction mixture was incubated with shaking $(400-600 \mathrm{rpm})$ at $40{ }^{\circ} \mathrm{C}$ for 3-24 h. The reaction progress was monitored by HPLC. The product peak was detected by UV-vis spectrum (red shift) and/or ESI-MS, as exemplified in Figures S5-S9. The conversion degrees were determined by measuring peak areas of the residual dyes and products at isosbestic points ( 1 and 2 - 309 nm, ASA - 304 nm, APTS - 299 nm). The reaction mixture was cooled to rt, diluted with $5 \mathrm{~mL}$ of TEAB buffer (1.0 M, pH 8), and purified by flash chromatography (C18 silica gel, 15C18AQ-F0025 cartridge, ACN - $20 \mathrm{mM}$ TEAB, $\mathrm{pH} 8,0-5 \% \mathrm{ACN}, 15$ column volumes). The appropriate fractions were pooled and concentrated in vacuo (rotary evaporator followed by speedvac). Glycoconjugates were usually handled as aqueous solutions (stored at $-20{ }^{\circ} \mathrm{C}$ ), and their constitution was confirmed using ESI-MS. The concentrations were determined by UV-vis (maxima between 295 and $317 \mathrm{~nm}$ ), where the extinction coefficients of 7,9diaminoacridines and 7-aminoacridones are roughly the same $\left(\varepsilon=30200 \pm 2500 \mathrm{M}^{-1} \mathrm{~cm}^{-1}\right)$.

Gel Electrophoresis. Gels were prepared using a $50 \mathrm{~mL}$ solution of $20 \%$ acrylamide in TBE buffer ( $89 \mathrm{mM}$ Tris, 89 $\mathrm{mM}$ borate, $2 \mathrm{mM}$ EDTA, $\mathrm{pH} 8.3$ ) containing $7 \mathrm{M}$ urea. Polymerization was initiated by the addition of $162 \mu \mathrm{L}$ of $\left(\mathrm{NH}_{4}\right)_{2} \mathrm{~S}_{2} \mathrm{O}_{8} \quad(25 \%$ in water $)$ and $44 \mu \mathrm{L}$ of $N, N, N^{\prime}, N^{\prime}$ tetramethylethylenediamine. The gels were of the 8- or 17well format (width $20 \mathrm{~cm}$ ) with $30 \mathrm{~cm}$ well-to-read length and $0.75 \mathrm{~mm}$ thickness. The running buffer was TBE. Electrophoresis was performed at a constant power of $35 \mathrm{~W}$ (Consort EV3330) and ambient temperature with cooling by air (ventilator); the front glass was covered with an external aluminum plate. After prerunning for $30 \mathrm{~min}$, the wells were thoroughly rinsed with TBE, and small volumes $(20-50 \mu \mathrm{L}$, ca. $50 \%$ formamide) of the samples were loaded. One gel lane between two samples was usually left free to avoid crosscontamination and ease the lane tracking. The electrophoresis voltage during separation was $1700-2200 \mathrm{~V}$, and the analysis was run until APTS reached the bottom of the gel (1.5-2 h). The bands of labeled carbohydrates were detected by emission in a UV viewing cabinet $(254 / 365 \mathrm{~nm})$ equipped with a digital camera or using Amersham Imager 600RGB.

\section{RESULTS AND DISCUSSION}

Design. The design of new and red-emitting fluorescent labels applicable in the reductive amination, separation, and fluorescent detection of glycans in CGE-LIF is limited by the availability of the suitable dye scaffolds. For example, bright "popular" dyes, such as rhodamines and cyanines, bleach upon reduction with borohydrides. ${ }^{30,31}$ To establish a design strategy, we considered our previously disclosed ASA (Figure $1)^{26}$ The introduction of a sulfonamide moiety into position 7 of 2-aminoacridone induced a red shift of ca. $60 \mathrm{~nm}$. The yellow-orange emitting 2-aminoacridone derivatives were shown to undergo reductive alkylation with saccharides. ${ }^{26}$ The high net charge $(z=-4)$ was provided by two primary 

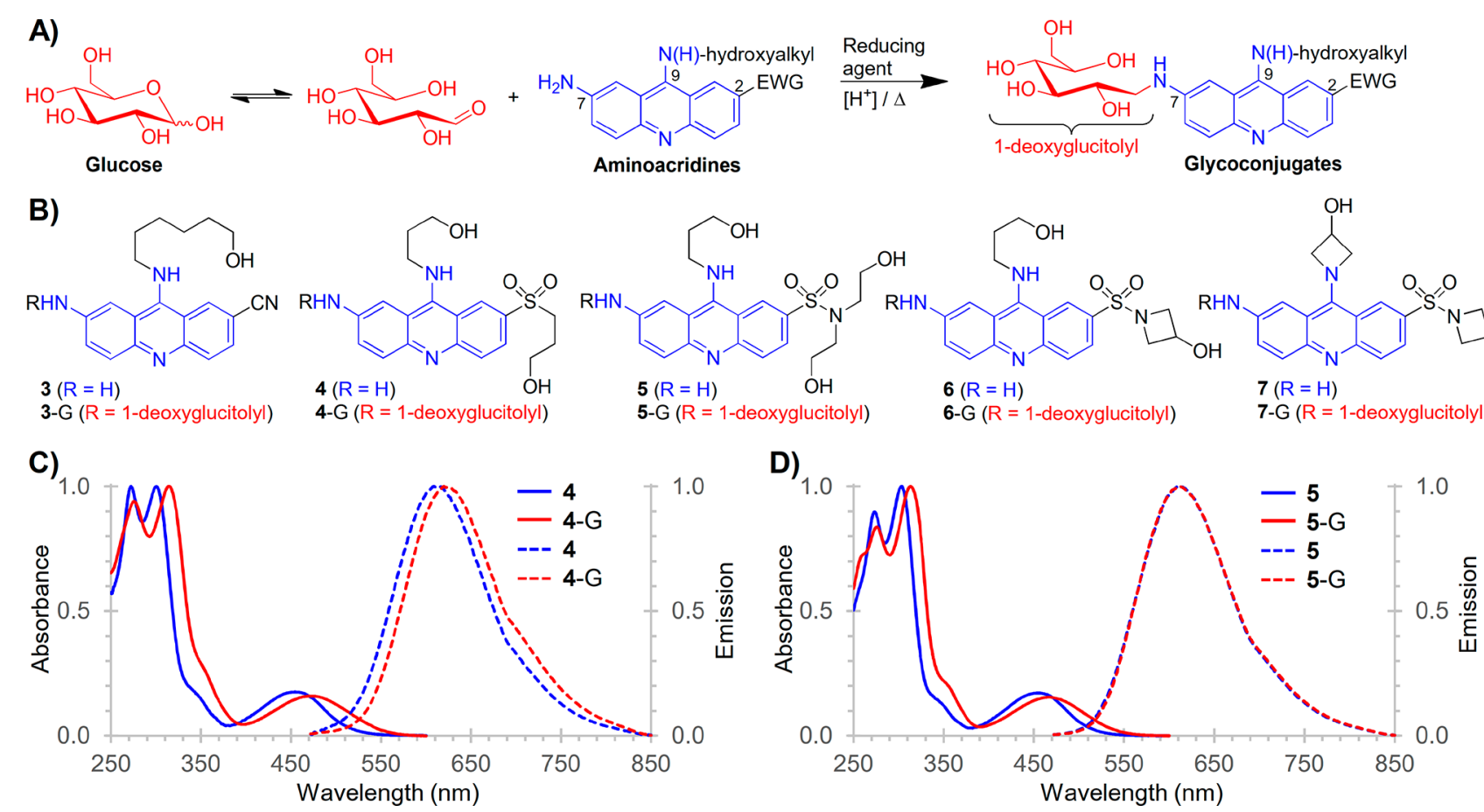

Figure 2. (A) Reductive amination of glucose with aminoacridines. (B) Model (unphosphorylated) 7,9-diaminoacridines (3-7) with electronacceptor cyano, alkylsulfonyl, and sulfonamido groups at C-2. (C, D) Normalized absorption (solid lines) and emission (dashed lines, $\lambda_{\text {exc }} 450 \mathrm{~nm}$ ) spectra in aqueous buffer (25 mM HEPES, pH 8): sulfone 4 and its conjugate 4-G; sulfonamide 5 and its conjugate 5-G.

phosphate groups $\left(\mathrm{R}-\mathrm{OPO}_{3} \mathrm{H}_{2}\right)$ and resulted in low $\mathrm{m} / \mathrm{z}$ ratio $(\sim 140)$. The combination of the donor (amino) and acceptor (sulfonamide) groups attached to the active positions of the acridone system (sites of the electrophilic attack) resulted in a push-pull $\pi$-electron system. The data from the literature suggested that a red-shift of the absorption and emission bands can be induced by transforming the acridone core of ASA into 9-aminoacridine one. ${ }^{32-34}$

The 7,9-diaminoacridine core is shown in Figure 2A. The amino group at C-9 can also participate in reductive amination, though it is less reactive than the amino group attached to C$7 .^{35}$ In order to exclude the possible competition between these amino groups and prevent hydrolysis at C-9, we decided to shield the amino group C-9 by alkylation. The monoalkylation is preferred, as 9-(monoalkylamino)acridines were reported to be more hydrolytically stable than 9(dialkylamino)derivatives. ${ }^{36}$ Another important feature is the presence of an electron-withdrawing group (EWG) at C-2. The optical spectra of acridines and the reactivity of an amino group at C-7 are sensitive to the electronic effects of the group attached to C-2. The electron-acceptor properties of the substituents can be assessed and compared on the basis of their $\sigma$-constants in the Hammett eq (Table S1). We decided to incorporate the strong electron-acceptor groups-cyano, sulfone and sulfonamide-into 7,9-diaminoacridine scaffold (at C-2). To confirm the proposed design, we synthesized acridines 3-7 without phosphate groups (Figure 2B, Schemes S2-S6). This allowed us to study the spectral properties and the feasibility of reductive amination.

Spectral Properties and Reductive Alkylation of the Model Compounds. We measured the absorption and fluorescent spectra of the free dyes in aqueous buffer (25 $\mathrm{mM}$ HEPES, $\mathrm{pH} 8$ ) and methanol (Table S2). The absorption spectra of compounds 4-7 in aqueous buffer have a broad band centered at $\lambda=455-460 \mathrm{~nm}$. Excitation in this low- energy range causes emission centered at $\lambda=603-626 \mathrm{~nm}$ with quantum yields of $2-5 \%$. Low emission efficiencies of dyes 4-7 are due to particularly large Stokes shifts (156-166 $\left.\mathrm{nm}, 5600-5770 \mathrm{~cm}^{-1}\right)$. In methanol smaller Stokes shifts of $111-120 \mathrm{~nm}\left(4000-4500 \mathrm{~cm}^{-1}\right)$ and larger fluorescence quantum yields of $17-25 \%$ were observed. Nitrile 3 was found to be unstable under neutral and basic conditions. Comparing sulfonamides $(5,6)$ with the structurally similar alkyl sulfone 4 , we observed no significant difference in the positions of absorption and emission bands. Compared with APTS (emission maximum at $503 \mathrm{~nm}$ in aqueous solutions), a remarkable red-shift of $100-113 \mathrm{~nm}$ was achieved.

The applicability of the dyes $(3-7)$ in reductive amination was explored by labeling glucose (Figure 2A,B and Scheme $\mathrm{S} 7$ ). Reaction of nitrile 3 with excess of glucose was carried out in $\mathrm{H}_{2} \mathrm{O}-\mathrm{MeOH}-\mathrm{AcOH}$ at $60{ }^{\circ} \mathrm{C}$ for $5 \mathrm{~h}$ using $\mathrm{NaBH}_{3} \mathrm{CN}$ as reducing agent. The HPLC-MS analysis confirmed the formation of a single product (Figure S1). Its constitution and structure were further proved by HRMS and NMR spectra. The characteristic signals of the reduced glucosamine moiety $\left(45.7 \mathrm{CH}_{2} \mathrm{~N}\right.$ and $62.9 \mathrm{CH}_{2} \mathrm{O}$ ppm) can be observed in ${ }^{13} \mathrm{C}$ NMR spectra $\left(\mathrm{D}_{2} \mathrm{O}, \mathrm{HSQC}\right)$ of compound 3-G (Figure $\mathrm{S} 2$ ). In contrast to the parent dye 3 , conjugate $3-\mathrm{G}$ was sufficiently stable, and this allowed us to acquire absorption and emission spectra at $\mathrm{pH}$ above 7 (Figure S3A). The reactivity of sulfone 4 and sulfonamides 5-7 was evaluated by performing reductive amination with equimolar amounts of glucose and using 2-picoline borane complex $\left(\right.$ pic- $\left.\mathrm{BH}_{3}\right)$ as a nontoxic alternative to $\mathrm{NaBH}_{3} \mathrm{CN} .^{37,38}$ In these experiments, we used mild labeling conditions adapted from Ruhaak et al. ${ }^{22}$ A clean conversion to the products (4-7-G) was detected (>80\% HPLC area).

The photophysical properties of the isolated glucose conjugates are given in Table S2. In aqueous buffer, the absorption maxima are found at about $470 \mathrm{~nm}$ and match a 
Scheme 1. Synthesis of Acridine Di- and Triphosphates $(1,2)$ and Acridone Diphosphate $(29)^{a}$

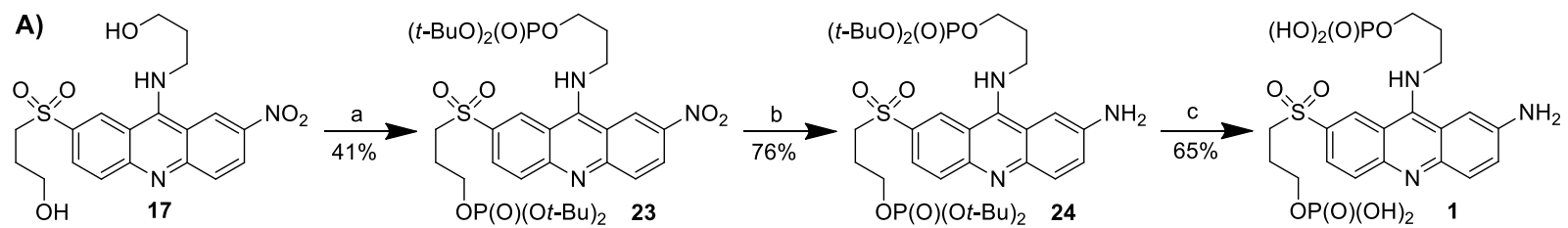<smiles>O=[N+]([O-])c1ccc2nc3ccc(S(=O)(=O)N(CCO)CCO)cc3c(NCCO)c2c1</smiles>

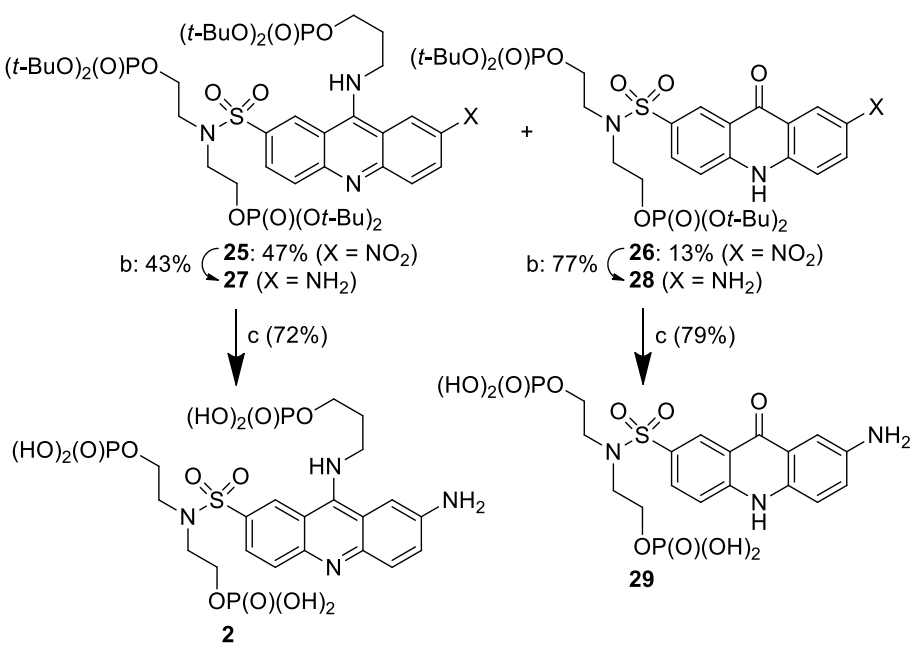

${ }^{a}$ Reagents and conditions: (a) 1. $1 \mathrm{H}$-tetrazole, $(t-\mathrm{BuO})_{2} \mathrm{PNi}-\mathrm{Pr}_{2}$, DMF, Ar. 2. $\mathrm{H}_{2} \mathrm{O}_{2}, \mathrm{H}_{2} \mathrm{O}$. (b) $\mathrm{H}_{2}, \mathrm{Pd} / \mathrm{C}, \mathrm{MeOH}-\mathrm{AcOH}$. (c) 5\% TFA, DCM.

$488 \mathrm{~nm}$ laser line better than the bands of the starting dyes. The conjugates with glucose emit orange-red light (with maxima at $610-630 \mathrm{~nm}$ ). The absolute values of the fluorescence quantum yields are $3-4 \%$. Conjugation with glucose results in bathochromic and/or bathofluoric shifts. For example, the absorption and emission maxima of glycosylated sulfone 4-G are red-shifted by 18 and $12 \mathrm{~nm}$, respectively (in aqueous solutions, Figure $2 \mathrm{C}$ ). In the case of sulfonamides (57-G), glycosylation does not shift the emission maxima to the red region but results in a bathochromic shift of 11-13 nm (Figure 2D and S3B,C). The observed bathochromic shifts can be explained by a stronger electron-donating effect of $\mathrm{N}$-alkyl groups versus the primary amino group. The orange-red emission of the acridine dyes is a remarkable feature, as this potentially enables detection of glycans without spectral crosstalk with APTS-labeled oligosaccharides. Acridines 4 and 5, as stable and more synthetically available compounds, were chosen for further development.

Synthesis of Phosphorylated Acridines. The phosphorylated analog of diol 4 was prepared according to the route given in Scheme 1A. Phosphorylation of diol 17 was performed using the general procedure introduced by Perich and Johns. ${ }^{39}$ For one hydroxyl group, it was mandatory to use 3 equiv of $1 \mathrm{H}$-tetrazole and 2 equiv of a phosphoramidite reagent. These conditions provided complete conversion of diol 17 to the intermediate bis-phosphite (formation monitored by HPLC), which was oxidized in the reaction mixture with aqueous hydrogen peroxide to alkylphosphate $\mathbf{2 3}$ (isolated in $41 \%$ yield). If the oxidation step was carried out with meta-chloroperbenzoic acid at room temperature, we observed the formation of many products, with acridine $\mathrm{N}$ oxide being the major one. Catalytic reduction of the nitro derivative $\mathbf{2 3}$ led to the amine $\mathbf{2 4}$. Both tert-butyl groups in compound 24 were cleaved upon treatment with 5\% TFA in DCM, and the target diphosphate $\mathbf{1}$ was isolated in a good yield. The final purification (reductive amination of glycans requires highly pure dyes) was achieved by reversed-phase chromatography using an aqueous TEAB buffer $(20 \mathrm{mM}, \mathrm{pH}$ 8).

In a similar fashion, acridine $\mathbf{2 0}$ with $\mathrm{N}, \mathrm{N}$-di(2hydroxyethyl)sulfonamido group was transformed into triphosphate $\mathbf{2}$ in three steps including phosphorylation, reduction, and deprotection (Scheme 1B). We observed that 7-aminoacridone-2-sulfonamide $\mathbf{2 6}$ was formed as a side product in the course of oxidation of phosphite intermediate (not shown) with peroxide. Therefore, we also prepared acridone diphosphate 29 for spectral comparison (Table 1).

Optical Properties and Application. To prove the applicability of phosphorylated acridines $\mathbf{1}$ and $\mathbf{2}$ in reductive amination and electrophoretic detection of glycans, we prepared their conjugates with glucose $(G)$, maltotriose $\left(G_{3}\right)$, and maltoheptaose $\left(G_{7}\right.$, see Figure $S 4$ for details). These sugars were selected, as in CGE-LIF applications, the migration of an analyte is often referenced to a ladder consisting of oligoglucoses labeled with APTS. ${ }^{27}$ Initially, these carbohydrates were labeled using equimolar amounts of acridines (final concentration $25 \mathrm{mM}$ ). A clean conversion to glycoconjugates was observed after $6 \mathrm{~h}$. Yields (HPLC areas of the product peaks) were in the range of $55-70 \%$, independent from the size of glucose oligomers (Figure S5). Longer incubation $(18-24 \mathrm{~h})$ led to the formation of minor amounts of hydrolysis byproducts, such as acridones. ${ }^{36} \mathrm{We}$ further compared the reactivity of acridines $(1,2)$ and the reference compounds (ASA and APTS) with 5 equiv of glucose. After $3 \mathrm{~h}$ of incubation, conversion to compounds 1-G and 2-G was quantitative (Figures S6, S7). At the same time, ASA and APTS showed only moderate conversion degrees of $45 \%$ and $35 \%$, respectively (Figures S8, S9). The double reductive alkylation of the dyes has not been detected. 
Table 1. Photophysical Properties of the Dyes and Their Conjugates with Glucose ${ }^{a}$

\begin{tabular}{|c|c|c|c|c|}
\hline comp. & solvent & $\left(\varepsilon, \mathrm{M}^{-1} \mathrm{~cm}^{-1}\right)^{b}$ & $\begin{array}{l}\lambda_{\mathrm{em}}, \mathrm{nm} \\
\left(\Phi_{\mathrm{f}}, \%\right)^{c}\end{array}$ & $\begin{array}{c}\Delta \nu_{\mathrm{St}}, \mathrm{nm} \\
\left(\mathrm{cm}^{-1}\right)\end{array}$ \\
\hline \multirow[t]{2}{*}{1} & $\mathrm{H}_{2} \mathrm{O}^{d}$ & $455(5100)$ & $629(1)$ & $174(6080)$ \\
\hline & $\mathrm{MeOH}^{e}$ & $468(4300)$ & $590(15)$ & $122(4418)$ \\
\hline \multirow[t]{2}{*}{$1-\mathrm{G}$} & $\mathrm{H}_{2} \mathrm{O}^{d}$ & 469 & $627(2)$ & $158(5373)$ \\
\hline & $\mathrm{MeOH}^{e}$ & 483 & $589(15)$ & $106(3726)$ \\
\hline \multirow[t]{2}{*}{2} & $\mathrm{H}_{2} \mathrm{O}^{d}$ & $455(5500)$ & $625(2)$ & $170(5978)$ \\
\hline & $\mathrm{MeOH}^{e}$ & $470(4800)$ & $586(11)$ & $116(4212)$ \\
\hline \multirow[t]{2}{*}{$2-\mathrm{G}$} & $\mathrm{H}_{2} \mathrm{O}^{d}$ & 466 & $626(2)$ & $160(5485)$ \\
\hline & $\mathrm{MeOH}^{e}$ & 480 & $583(14)$ & $103(3681)$ \\
\hline \multirow[t]{2}{*}{29} & $\mathrm{H}_{2} \mathrm{O}^{d}$ & $422(3900)$ & $583(7)$ & $161(6544)$ \\
\hline & $\mathrm{MeOH}^{e}$ & $428(3500)$ & $562(20)$ & $134(5571)$ \\
\hline \multirow[t]{2}{*}{ ASA } & $\mathrm{H}_{2} \mathrm{O}^{d}$ & $431(5200)$ & $593(4)$ & $162(6338)$ \\
\hline & $\mathrm{MeOH}^{e}$ & $435(4900)$ & $575(15)$ & $140(5597)$ \\
\hline \multirow[t]{2}{*}{ ASA-G } & $\mathrm{H}_{2} \mathrm{O}^{d}$ & 439 & $597(4)$ & $158(6029)$ \\
\hline & $\mathrm{MeOH}^{e}$ & 448 & $583(12)$ & 135 (5169) \\
\hline
\end{tabular}

${ }^{a}$ For details, see Table S3 and Figure S3D-G in the Supporting Information. ${ }^{b}$ Absorption maximum with the longest wavelength. ${ }^{c}$ Absolute values of the fluorescence quantum yields. ${ }^{d}$ HEPES buffer (25 mM, pH 8.0). ${ }^{e} \mathrm{MeOH}$ with $0.1 \%$ TEA.

Under this mild conditions (25 mM dye, $40{ }^{\circ} \mathrm{C}$, short incubation of 3-6 h), the reductive alkylation of the new aminoacridines proceeds cleanly, with high yields, and more readily than that of APTS. However, the labeling efficiency can be further improved by increasing the dye concentration in the reaction mixture; for example, by using evaporative reductive amination. $^{25,40}$ To prove this, we performed additional reactions with varied amounts of maltoheptaose (0.5-1 equiv). Without applying evaporative conditions, the labeling yield varied between 60 and $70 \%$, irrespective from the amount of maltoheptaose. However, under evaporative conditions, we observed $20-30 \%$ increase in labeling efficiency (Figure S10A). The conversion was high, and the reaction was clean (Figure S10B). No large excess of the dye was necessary. The latter is important for practical applications, as excess dye might interfere with the analyte detection.

Spectral properties of the dyes 1, 2, ASA, their conjugates with glucose, and acridone $\mathbf{2 9}$ are given in Table 1. The emission colors observed for the pyrene (APTS), acridone (ASA) and acridine (1) dyes are clearly different (Figure 3A). The absorbance and emission curves for glycoconjugates are given in Figure 3B. The emission maxima of acridines $\mathbf{1}$ and $\mathbf{2}$ showed a red shift of 13-18 $\mathrm{nm}$ in comparison to the unphosphorylated dyes 4 and 5 (Table S2), respectively. Glycosylation did not shift the emission maxima to the red, but resulted in a bathochromic shift of 11-14 nm (Stokes shifts decreased; emission efficiencies somewhat increased). The absorption maxima of conjugates were found at 466-469 nm and matched the $488 \mathrm{~nm}$ excitation laser line better than the bands of the starting dyes. Compared with acridone ASA-G, the acridine analogue $1-G$ showed red shifts in the absorption $(30 \mathrm{~nm})$ and emission maxima $(30 \mathrm{~nm})$. Importantly, emissions of the carbohydrate derivatives of acridines and APTS can be readily separated with minimal spectral overlap.

The structures, reactivity toward reducing sugars and spectral properties encouraged us to investigate the applicability of acridines $\mathbf{1}$ and $\mathbf{2}$ in gel electrophoresis analysis. First, we confirmed the stability of the free dyes and their glucose conjugates in the course of PAGE (Figure S11). The
A)

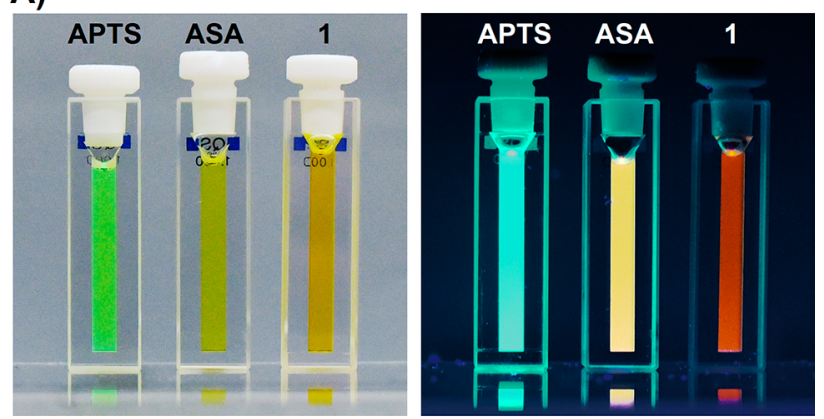

B)

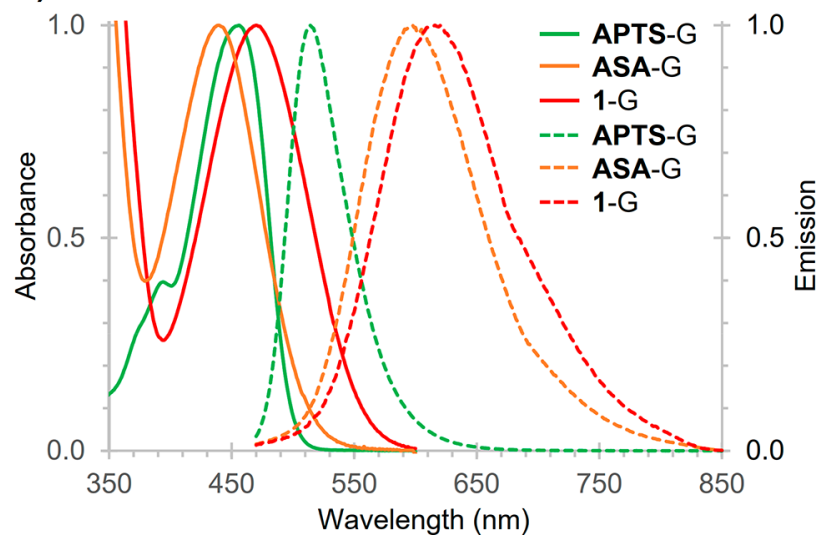

Figure 3. (A) Photographic images of the dye solutions at $\mathrm{pH} 8$ (left, ambient light) and under illumination with UV lamp at $365 \mathrm{~nm}$ (right). (B) Normalized absorption (solid lines) and emission spectra (dashed lines, $\lambda_{\text {exc }} 450 \mathrm{~nm}$ ) in aqueous buffer $(25 \mathrm{mM}$ HEPES, $\mathrm{pH}$ 8): glucose conjugates of pyrene (APTS-G), acridone (ASA-G), and acridine (1-G) dyes.

substances were recovered from gel slices and analyzed by HPLC and ESI-MS to prove their integrity. Additionally, it was necessary to estimate the mobility of free dyes and their conjugates in an electric field. We used APTS as a reference dye. Compound ASA was used as an analogue of and comparison to compound 1 . Both of them have four negative charges and a mass difference of only 2 Da. Figure 4A shows the migration pattern of the free dyes and their glycoconjugates. Gel bands of acridine glycoconjugates appear red instead of the characteristic orange color of free dyes $\mathbf{1}$ and 2 . Relative mobility units (RMU) for individual spots were calculated (Table S4). We assumed that the electrophoretic mobilities of the large labeled oligosaccharides $\left(G_{3}, G_{7}\right)$ are inversely proportional to their $m / z$. Glycoconjugates of diphosphate dye 1 migrate slower than the corresponding derivatives prepared from ASA dye. This indicates that the absolute value of the net charge is smaller for dye $\mathbf{1}(-3)$ than for dye ASA $(-4)$ at $\mathrm{pH}$ 8.3. The $\mathrm{p} K_{\mathrm{a}}$ values of the structurally similar acridines indicate that an acridine moiety may be protonated at $\mathrm{pH} 8.3 .^{41}$ The $\mathrm{pH}$ titration of acridine 1-G revealed a fluorescence enhancement (53\%) and an emission blue-shift of $19 \mathrm{~nm}$ with $\mathrm{pH}$ increasing from 8 to 9 (Figure S12). On the contrary, the $\mathrm{pH}$ titration profile of acridone ASA-G showed only a slight increase (2\%) and no emission shift (Figure S13). If we assume that the protonation of acridine moiety takes place for dye $\mathbf{1}$ and other 9-aminoacridines, then triphosphate dye $\mathbf{2}$ and its conjugates with "neutral" glycans must have 5 negative charges. As expected, the larger conjugates of triphosphate dye 2 move faster than the structurally similar derivatives of APTS 
A)

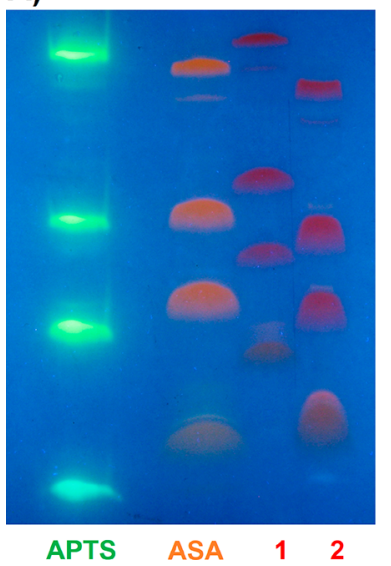

B)

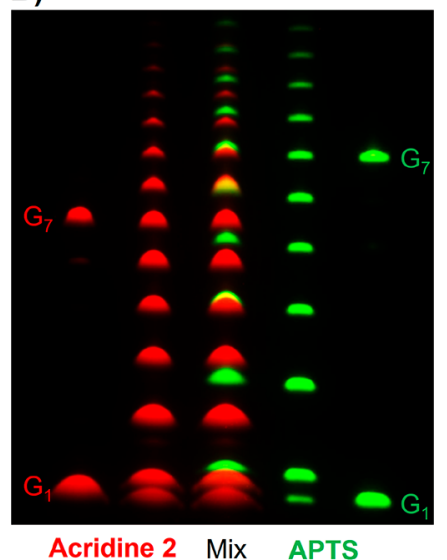

Figure 4. Gel electrophoresis results (migration from "north" to "south", $\mathrm{pH}$ 8.3). (A) From bottom to top, free dyes and their conjugates with glucose, maltotriose, maltoheptaose for each lane. Impurities in maltoheptaose give additional (weak) bands. Sample: 25 nmol of each carbohydrate, except ones labeled with APTS (5 nmol). The gel was visualized using a UV transilluminator and digital camera (excitation at $365 \mathrm{~nm}$ ). (B) Maltodextrin ladder labeled either with APTS ( $5 \mathrm{nmol}$; green bands) or acridine-triphosphate $2(30 \mathrm{nmol}$; red spots), referenced to glucose $\left(G_{1}\right)$ and maltoheptaose $\left(G_{7}\right)$ standards (1 nmol APTS, $8 \mathrm{nmol}$ acridine 2). Signals resolved using an Amersham Imager 600RGB. "Green" channel: excitation $460 \mathrm{~nm}$, emission collected: $515-535 \mathrm{~nm}$, exposure $0.1 \mathrm{~s}$; "red" channel: excitation $520 \mathrm{~nm}$, emission collected: $585-625 \mathrm{~nm}$, exposure $3.7 \mathrm{~s}$.

and ASA, which corresponds to the presence of five negative charges. However, due to larger hydrodynamic radius, the free dye $\mathbf{2}$ moves slower than APTS and ASA.

Reductive amination of maltodextrin oligosaccharides (DP2 to DP15, Carbosynth) with dye 2 demonstrated its high reactivity and usefulness in complex carbohydrate analysis. We also labeled the same maltodextrin ladder with APTS as a reference dye. Images were collected using a standard gel imaging system (Amersham Imager 600RGB), which allows multicolor detection (Figure 4B), and using a UV excitation source coupled with a digital camera (Figure S14A). APTS and acridine 2 labeled maltodextrin standards showed very dissimilar migration patterns. The bands of individual saccharides were well resolved and detectable up to $G_{12}$, even when both ladders were mixed and applied into the same lane (Figure 4B, Mix). Larger oligosaccharide derivatives $\left(G_{2}\right.$, $\mathrm{G}_{3}, \mathrm{G}_{4}$, etc.) of dye 2 migrate faster than those of APTS. Importantly, we observed no emission from the conjugates of compound 2 in the "green" (APTS) detection window (515 to $535 \mathrm{~nm}$, Figure S14B). Therefore, phosphorylated aminoacridine dyes, as exemplified by compound 2 , are suitable for producing new internal standards based on carbohydrates. The short distances between the bands are expected to provide high precision in pinpointing the analyte peaks.

We also demonstrated the separation of two sialyllactose isomers derivatized with compound $\mathbf{1}$ (Figure S15). Conjugate 1-3SL (Neu5Ac $(\alpha 2-3)$ Gal $(\beta 1-4)$ Glc-1 $)$ migrates slower than its isomer 1-6SL (Neu5Ac $(\alpha 2-6) \mathrm{Gal}(\beta 1-4) \mathrm{Glc}-1)$. The two trisaccharides differ only by their $N$-acetylneuraminic acid (Neu5Ac) linkages at the nonreducing ends. This illustrates that the new dyes are promising in respect of their "resolving power".

Acridine 1 was applied for labeling of $\mathrm{N}$-acetylamino sugars ( $\mathrm{N}$-acetylglucosamine and $\mathrm{N}$-acetylgalactosamine), which are

found at the reducing end of the $\mathrm{N}$ - and $\mathrm{O}$-linked oligosaccharides in glycoproteins. These sugars are considered "difficult" to label, and citric acid catalyst and elevated temperatures are required to achieve high conversion degrees with APTS. ${ }^{42}$ A facile reaction of dye 1 with 5 equiv of $N$ acetylamino sugars was observed under mild conditions. The reaction with $N$-acetylgalactosamine (GalNAc) was nearly complete in $3 \mathrm{~h}$, giving a 90\% yield (HPLC area) of conjugate 1-GalNAc (Figure S16). In the case of $\mathrm{N}$-acetylglucosamine (GlcNAc), a prolonged incubation for $24 \mathrm{~h}$ was required giving a $73 \%$ yield of 1 -GlcNAc (Figure S17). On the contrary, APTS gave the lower labeling yields either reacted with GlcNAc (19\% after $24 \mathrm{~h}$ ) or GalNAc (70\% after $24 \mathrm{~h}$ ) under these conditions (Figure S18). As fucose is a common modification of $\mathrm{N}$ glycans at the reducing end, we also labeled the GlcNAc sugars containing fucosyl residues with various linkages such as Fuc $(\alpha 1-3)$ GlcNAc, Fuc $(\alpha 1-6)$ GlcNAc, and Fuc $(\alpha 1-2)$ Gal$(\beta 1-4)[\mathrm{Fuc}(\alpha 1-3)]$ GlcNAc. Even under mild conditions, acridine 1 was efficiently conjugated both to the disaccharides (53\%) and to the tetrasaccharide (28\%, Figure S19). Thus, acridines can be useful for fluorescent labeling of glycans from proteins or sugars having low reactivity toward conventional reagents as APTS. Further studies with highly sensitive CGELIF will help to find optimal conditions for labeling of glycans of various origin.

\section{CONCLUSIONS}

We designed and synthesized a series of seven red-emitting and highly reactive fluorescent tags for glycan derivatization via reductive amination. The negatively charged dyes $(1,2)$ remove the monopoly of APTS as the unique fluorescent tag for electrophoretic glycan analysis. They offer new dimensions (with respect to Stokes shift, emission color, and high mobility in electric field) for the analysis of natural carbohydrates. Moreover, the red-emission of conjugates (with a maximum at about $630 \mathrm{~nm}$ ), observed under excitation with $488 \mathrm{~nm}$ light, allows easy and reliable separation from the green fluorescent signal of APTS-labeled saccharides. Further experiments on multiplexed CGE-LIF (utilizing a DNA-sequencer) are expected to reveal their utility for precise glycan identification. We expect that the new dyes will be helpful for applications that benefit from having multiple tags, such as profiling of individual isomers of biologically or clinically important glycans (e.g., high-mannose oligosaccharides), known for their "difficult" separation patterns. ${ }^{13}$ Since these dyes are complementary to APTS, they are also expected to enhance performance of existing applications by creating a new set of internal standards. ${ }^{27}$ We are confident the new reagents will open the door to new opportunities for $\mathrm{N}$-glycan profiling by CGE-LIF.

\section{ASSOCIATED CONTENT}

\section{Supporting Information}

The Supporting Information is available free of charge at https://pubs.acs.org/doi/10.1021/acs.analchem.9b05863.

Synthetic procedures and characterization of all new compounds, evaporative reductive amination, HPLC traces, NMR spectra; supplementary Schemes S1-S7, Tables S1-S4, and Figures S1-S20 (PDF) 


\section{AUTHOR INFORMATION}

\section{Corresponding Author}

Vladimir N. Belov - Department of NanoBiophotonics, Max Planck Institute for Biophysical Chemistry (MPIBPC), 37077 Göttingen, Germany; 0 orcid.org/0000-0002-7741-4653; Email: vladimir.belov@mpibpc.mpg.de

\section{Authors}

Maksim A. Fomin - Department of NanoBiophotonics, Max Planck Institute for Biophysical Chemistry (MPIBPC), 37077 Göttingen, Germany

Jan Seikowski - Facility for Synthetic Chemistry, MPIBPC, 37077 Göttingen, Germany

Stefan W. Hell - Department of NanoBiophotonics, Max Planck Institute for Biophysical Chemistry (MPIBPC), 37077 Göttingen, Germany; 이이이.org/0000-0002-9638-5077

Complete contact information is available at:

https://pubs.acs.org/10.1021/acs.analchem.9b05863

\section{Notes}

The authors declare no competing financial interest.

\section{ACKNOWLEDGMENTS}

The authors are grateful to Ms. Elizaveta Savicheva (MPIBPC) for providing APTS conjugates, Mr. Jürgen Bienert (MPIBPC) for recording NMR and ESI mass-spectra. The authors are thankful to Dr. H. Frauendorf and his team (Institut für Organische und Biomolekulare Chemie, Georg-August-Universität Göttingen) for recording high-resolution mass-spectra.

\section{REFERENCES}

(1) Pinho, S. S.; Reis, C. A. Nat. Rev. Cancer 2015, 15, 540-555.

(2) Ruhaak, L. R.; Miyamoto, S.; Lebrilla, C. B. Mol. Cell. Proteomics 2013, 12, 846-855.

(3) Reusch, D.; Haberger, M.; Maier, B.; Maier, M.; Kloseck, R.; Zimmermann, B.; Hook, M.; Szabo, Z.; Tep, S.; Wegstein, J.; Alt, N.; Bulau, P.; Wuhrer, M. mAbs 2015, 7, 167-179.

(4) Reusch, D.; Haberger, M.; Kailich, T.; Heidenreich, A.-K.; Kampe, M.; Bulau, P.; Wuhrer, M. mAbs 2014, 6, 185-196.

(5) Reusch, D.; Haberger, M.; Falck, D.; Peter, B.; Maier, B.; Gassner, J.; Hook, M.; Wagner, K.; Bonnington, L.; Bulau, P.; Wuhrer, M. $m A b s$ 2015, 7, 732-742.

(6) Rudd, P. M.; Elliott, T.; Cresswell, P.; Wilson, I. A.; Dwek, R. A. Science 2001, 291, 2370-2376.

(7) Griffin, M. E.; Hsieh-Wilson, L. C. Cell Chem. Biol. 2016, 23, $108-121$.

(8) Ruhaak, L. R.; Xu, G.; Li, Q.; Goonatilleke, E.; Lebrilla, C. B. Chem. Rev. 2018, 118, 7886-7930.

(9) Lu, G.; Crihfield, C. L.; Gattu, S.; Veltri, L. M.; Holland, L. A. Chem. Rev. 2018, 118, 7867-7885.

(10) Guttman, A.; Pritchett, T. Electrophoresis 1995, 16, 1906-1911.

(11) Evangelista, R. A.; Liu, M.-S.; Chen, F.-T. A. Anal. Chem. 1995, 67, 2239-2245.

(12) Laroy, W.; Contreras, R.; Callewaert, N. Nat. Protoc. 2006, 1, 397-405.

(13) Feng, H.-T.; Li, P.; Rui, G.; Stray, J.; Khan, S.; Chen, S.-M.; Li, S. F. Y. Electrophoresis 2017, 38, 1788-1799.

(14) Callewaert, N.; Geysens, S.; Molemans, F.; Contreras, R. Glycobiology 2001, 11, 275-281.

(15) Novotny, M. V.; Alley, W. R., Jr. Curr. Opin. Chem. Biol. 2013, 17, 832-840.

(16) Volpi, N. Capillary Electrophoresis of Carbohydrates: From Monosaccharides to Complex Polysaccharides; Humana Press: New York, 2011; pp 1-55.
(17) Ruhaak, L. R.; Zauner, G.; Huhn, C.; Bruggink, C.; Deelder, A. M.; Wuhrer, M. Anal. Bioanal. Chem. 2010, 397, 3457-3481.

(18) Baxter, E. W.; Reitz, A. B. Reductive Aminations of Carbonyl Compounds with Borohydride and Borane Reducing Agents. In Organic Reactions; Overman, L. E., Ed.; Joh Wiley \& Sons: New York, 2002; Vol. 59, pp 1-125.

(19) Mantovani, V.; Galeotti, F.; Maccari, F.; Volpi, N. Electrophoresis 2018, 39, 179-189.

(20) Suzuki, H.; Müller, O.; Guttman, A.; Karger, B. L. Anal. Chem. 1997, 69, 4554-4559.

(21) Sharrett, Z.; Gamsey, S.; Hirayama, L.; Vilozny, B.; Suri, J. T.; Wessling, R. A.; Singaram, B. Org. Biomol. Chem. 2009, 7, 1461-1470.

(22) Ruhaak, L. R.; Hennig, R.; Huhn, C.; Borowiak, M.; Dolhain, R. J. E. M.; Deelder, A. M.; Rapp, E.; Wuhrer, M. J. Proteome Res. 2010, 9, 6655-6664.

(23) Bunz, S.-C.; Cutillo, F.; Neusüß, C. Anal. Bioanal. Chem. 2013, 405, 8277-8284.

(24) Pabst, M.; Kolarich, D.; Pöltl, G.; Dalik, T.; Lubec, G.; Hofinger, A.; Altmann, F. Anal. Biochem. 2009, 384, 263-273.

(25) Savicheva, E.; Mitronova, G.; Thomas, L.; Böhm, M.; Seikowski, J.; Belov, V.; Hell, S. Negatively charged yellow-emitting 1 -aminopyrene dyes for reductive amination and fluorescence detection of glycans. Angew. Chem. 2020, DOI: 10.1002/ ange.201908063.

(26) Hell, S. W.; Belov, V. N.; Bischoff, M.; Meineke, D.; Thomas, L.; Mitronova, G.; Savicheva, E.; Kolmakov, K.; Böhm, M. J.; Rapp, E. EP patent application nr. PCT/EP2019/051396 (filed on Jan. 21, 2019).

(27) Mittermayr, S.; Guttman, A. Electrophoresis 2012, 33, 10001007.

(28) Zhou, W.; Gee, K.; Tennico, Y.; Slade, P.; Kang, H. C.; Khan, S.; Evans, B.; Stray, J. Hydrazinyl and aminooxy compounds and their methods of use. U.S. Patent 2017/0369431 A1, Dec. 28, 2017.

(29) Rapp, E.; Schwarzer, J.; Reichl, U.; Bohne, C. Method for automated high throughput identification of carbohydrates and carbohydrate mixture composition patterns as well as systems therefore. European Patent 2112506 A1, 28. Oct., 2009.

(30) Kundu, K.; Knight, S. F.; Willett, N.; Lee, S.; Taylor, W. R.; Murthy, N. Angew. Chem., Int. Ed. 2009, 48, 299-303.

(31) Carlini, L.; Benke, A.; Reymond, L.; Lukinavičius, G.; Manley, S. ChemPhysChem 2014, 15, 750-755.

(32) Skripkina, V. T.; Dykhanov, N. N.; Maksimets, V. P.; Shcherbak, L. D. Chem. Heterocycl. Compd. 1971, 7, 107-109.

(33) Szymanska, A.; Wiczk, W.; Lankiewicz, L. Chem. Heterocycl. Compd. 2000, 36, 801-808.

(34) Yang, P.; Yang, Q.; Qian, X.; Tong, L.; Li, X. J. Photochem. Photobiol., B 2006, 84, 221-226.

(35) Gellerman, G.; Gaisin, V.; Brider, T. Tetrahedron Lett. 2010, 51, 836-839.

(36) Goodell, J. R.; Svensson, B.; Ferguson, D. M. J. Chem. Inf. Model. 2006, 46, 876-883.

(37) Sato, S.; Sakamoto, T.; Miyazawa, E.; Kikugawa, Y. Tetrahedron 2004, 60, 7899-7906.

(38) Ruhaak, L. R.; Steenvoorden, E.; Koeleman, C. A. M.; Deelder, A. M.; Wuhrer, M. Proteomics 2010, 10, 2330-2336.

(39) Perich, J. W.; Johns, R. B. Synthesis 1988, 1988, 142-144.

(40) Reider, B.; Szigeti, M.; Guttman, A. Talanta 2018, 185, 365369.

(41) Albert, A.; Goldacre, R. J. Chem. Soc. 1946, 706-713.

(42) Bui, A.; Kocsis, B.; Kilár, F. J. Biochem. Biophys. Methods 2008, $70,1313-1316$. 